\title{
NORFLOXACIN RESISTANT BACTERIAL COMPOSITIONS IN SEDIMENTS OF CHINESE SUBTROPICAL FISH PONDS
}

\author{
MAO, L. T. ${ }^{1 *}-$ HuANG, J. ${ }^{1}-$ CHEN, Z. G. ${ }^{1}-$ MA, X. L. ${ }^{1}-$ LIU, H. R. ${ }^{2}$ \\ ${ }^{1}$ School of Life Science, Huizhou University, Huizhou 516007, China \\ ${ }^{2}$ School of Chemistry and Materials Engineering, Huizhou University, Huizhou 516007, China \\ *Corresponding author \\ e-mail: mlt@hzu.edu.cn; phone: +86-752-252-9555
}

(Received 12 $2^{\text {th }}$ Sep 2018; accepted $22^{\text {nd }}$ Nov 2018)

\begin{abstract}
Antibiotic resistant bacteria are widely spread in environments. However, the compositions of bacteria with antibiotic resistance in subtropical fish pond sediment are still unclear. In present study, to analyze the compositions of norfloxacin resistant bacteria in subtropical fish pond sediments, we selectively cultured the sediment bacteria collected from six subtropical fish ponds located in southern China using the basic medium with $50 \mu \mathrm{g} / \mathrm{ml}$ of norfloxacin, and analyzed their compositions using MiSeq high-throughput sequencing of 16S rRNA gene amplicons. Our results showed that various norfloxacin resistant bacteria existed in the fish pond sediments. And most of them were Gram-negative bacteria. Their spatial distribution was mainly influenced by environmental heterogeneity of the ponds. These results implied that norfloxacin resistance was widespread in Gram-negative bacteria in the fish pond sediments located in southern China. These finding provided reference information to prevent fish infected diseases and to assess the risk of antibiotic resistant bacteria in the fish pond sediments.

Keywords: antibiotic, bacterial community, environmental heterogeneity, Gram-negative bacteria, highthroughput sequencing
\end{abstract}

\section{Introduction}

Bacterial pathogens are the major cause of infectious diseases and mortality in wild and farmed fish (Sudheesh et al., 2012). Disease problems constitute that the largest single cause of economic losses in aquaculture (Meyer, 1991). With the rapid growth and intensification of aquaculture, the list of new pathogenic bacterial species isolated from fish has been steadily increasing (Harvell et al., 1999). To control the pathogenic bacteria and enhance fish growth, antibiotics have been widely used in agricultural production over the past decades (Ma et al., 2001; Neela et al., 2015). However, extensive use of antibiotics, especially the overuse of antibiotics in agricultural production, has caused a serious threat of antibiotic resistance (Levy and Marshall, 2004; Goossens et al., 2005; Mathew et al., 2007; Kumarasamy et al., 2010; Laxminarayan et al., 2013). Although the usage of antibiotics in agricultural production is strictly restricted presently, residues of antibiotics in environment and illegal use of antibiotics still cause prevalence of antibiotic resistance, especially in the aquatic systems, such as lakes and fish ponds (Wahid et al., 2014; Moore et al., 2014; Far et al., 2015; Neela et al., 2015; Patil et al., 2016; Yang et al., 2016). In addition, there are many antibiotics used in aquaculture, such as terramycin, also used in clinical trials in China (Ma et al., 2001).

Pond culture is one of the most prevailing culture patterns in China, which is the largest producing area of aquatic products around the world (FAO, 2014; Lu et al., 2015). Sewage discharge and agricultural production cause residues of antibiotics in ponds (Lin et al., 2010; Zhang et al., 2011; Wei et al., 2011; Song et al., 2016; Cheng et 
al., 2016). These residues of antibiotics increased the risk of antibiotic resistance. Although the genes of antibiotic resistance in the ponds have been widely investigated (Cheng et al., 2016), and a lot of antibiotic resistance bacteria have been isolated from many ponds (Zhang et al., 2011; Wei et al., 2011; Neela et al., 2015), the compositions of bacteria with antibiotic resistance in the ponds are still unclear.

Screening antibiotic resistant bacteria through culturing by mediums containing antibiotics is commonly used method to study antibiotic resistant bacteria (Kumarasamy et al., 2010; Neela et al., 2015; Li et al., 2017). However, the previous studies mostly focused on signal or few bacterial species. Although high-throughput sequencing technology has been widely used in microbial community analysis (Huang et al., 2018; Ni et al., 2018; Xiang et al., 2018), it is still not to use to investigate composition of antibiotic resistant bacteria in pond sediment.

Norfloxacin is commonly used antibiotic in aquaculture and is frequently detected from various water environments and aquatic animals (Ortiz et al., 1999; Guo and Zhang, 2009; Spongberg et al., 2011; Zhang et al., 2017). To analyze the compositions of antibiotic resistant bacteria in pond sediment, we selectively cultured the sediment bacteria collected from six subtropical fish ponds in southern China using the basic medium containing with norfloxacin and analyzed their compositions using MiSeq high-throughput sequencing of 16S rRNA gene amplicons. Results of the present study provided reference information to prevent fish infective diseases and assess the risk of antibiotic resistance in Chinese subtropical fish ponds.

\section{Materials and methods}

\section{Sampling collection and treatment}

Sediment samples were collected from 5 fish ponds (GraA, GraF, LatF, GruF, and OreD) located in Yuanzhou Town $\left(113^{\circ} 57^{\prime} \mathrm{E}, 23^{\circ} 07^{\prime} \mathrm{N}\right)$ and 1 fish pond (ChiP) located in Huicheng District $\left(114^{\circ} 23^{\prime} \mathrm{E}, 23^{\circ} 05^{\prime} \mathrm{N}\right)$ of Huizhou, a subtropical city in southern China on January 22, 2016 (Fig. 1). Fish species farmed in the ponds were showed in Table 1. Three sediment samples were parallelly collected from each pond. Five-point sampling method was used to collect each sediment sample (i.e., five sub-samples were collected at area within $1 \mathrm{~m}$ of diameter, and then pooled together with an equal wet weight as one sample).

Table 1. Fish species farmed in the ponds. All fish ponds located in Huizhou, a subtropical city in southern China

\begin{tabular}{c|c|c|c}
\hline Pond name & Pond location & Pond surface area $\left.\mathbf{( m}^{\mathbf{2}}\right)$ & Fish species \\
\hline GraA & Yuanzhou Town & 4,330 & $\begin{array}{c}\text { Grass carp (Ctenopharyngodon idellus) } \\
\text { and tilapia (Tilapia mossambica) }\end{array}$ \\
GraF & Yuanzhou Town & 3,000 & Fries of grass carp \\
LatF & Yuanzhou Town & 3,330 & Weever (Lateolabrax japonicus) \\
GruF & Yuanzhou Town & 2,330 & Crucian carp (Carassius auratus) \\
OreD & Yuanzhou Town & 4,670 & Tilapia (Tilapia mossambica) \\
ChiP & Huicheng District & 5,330 & A mixture of multiple fishes \\
\hline
\end{tabular}




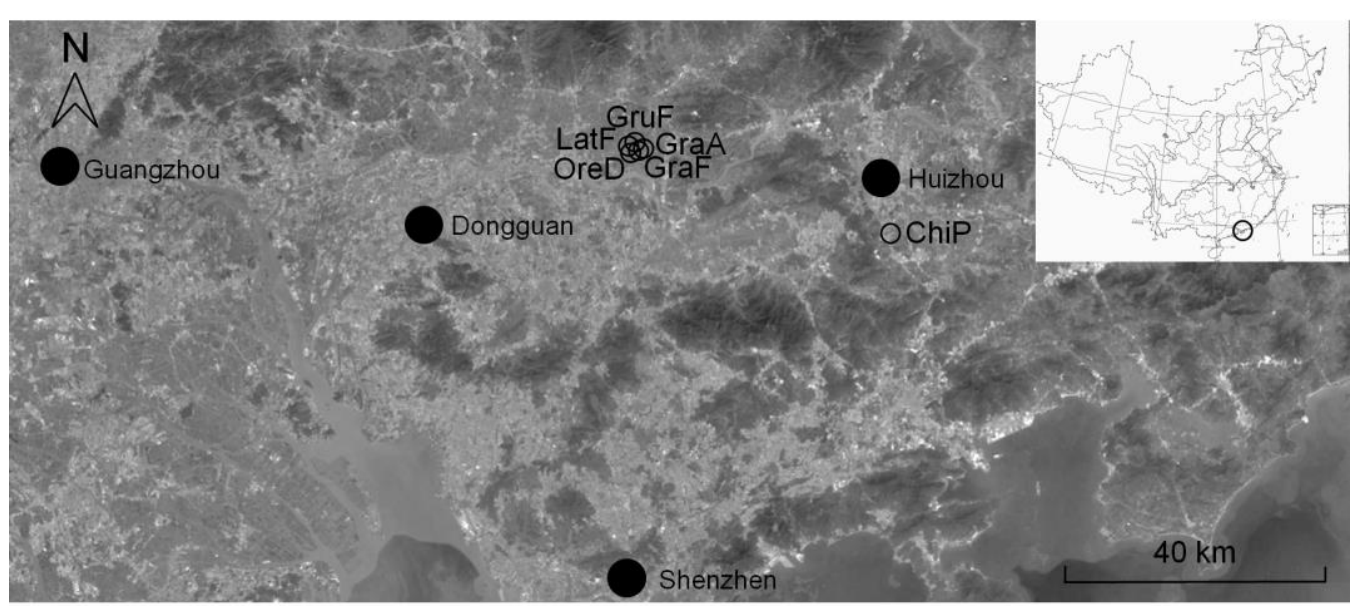

Figure 1. Distribution of sampling ponds. Hollow circles show the sampling ponds, and black spots show the major cities around the sampling ponds

Triplicate $1 \mathrm{~g}$ of sediments (wet weight) of each sample were added into conical flask containing $100 \mathrm{ml}$ of the basic medium with $50 \mu \mathrm{g} / \mathrm{ml}$ of norfloxacin referenced a previous report (Ma et al., 2012) and were cultured $24 \mathrm{~h}$ at $30^{\circ} \mathrm{C}$ in an incubator with $150 \mathrm{r} / \mathrm{min}$. Then the inoculums were centrifugated $10 \mathrm{~min}$ at $1200 \mathrm{rpm}$ to concentrate and the suspensions were transferred into $2 \mathrm{ml}$ centrifuge tubes for microbial DNA extraction. The microbial DNA were extracted according to previous description (Fang et al., 2015) and purified using a gel extraction kit (Dingguo, China). DNA concentrations were measured using a Nanodrop 2000 spectrophotometer and diluted to $10 \mathrm{ng} / \mu \mathrm{l}$ for PCR amplification.

\section{PCR amplification and sequencing}

V4-V5 hypervariable region of 16S rRNA gene was amplified and sequenced using a MiSeq system, as described previously (Ni et al., 2017; Huang et al., 2018; Xiang et al., 2018). Briefly, the V4-V5 region was amplified using the universal primer pair $515 \mathrm{~F}$ (5' - GTG YCA GCM GCC GCG GTA - 3') and 909R (5' - CCC CGY CAA TTC MTT TRA GT - 3') with a 12-nucleotide sample-specific barcode included at the 5'-end of the $515 \mathrm{~F}$ sequence to distinguish samples. PCR was conducted in duplicate with $25-\mu 1$ reaction mix containing $1 \times$ buffer, $0.25 \mathrm{U}$ of Taq DNA polymerase (Transgen, China), $0.2 \mathrm{mM}$ of each $\mathrm{dNTP}, 1.0 \mu \mathrm{M}$ of each primer and $10 \mathrm{ng}$ DNA. The PCR procedure consisted of a pre-denaturation step at $94{ }^{\circ} \mathrm{C}$ for $10 \mathrm{~min}$, followed by 30 cycles of $94{ }^{\circ} \mathrm{C}$ for $30 \mathrm{~s}, 56^{\circ} \mathrm{C}$ for $30 \mathrm{~s}$ and $72{ }^{\circ} \mathrm{C}$ for $30 \mathrm{~s}$ and a final extension at $72{ }^{\circ} \mathrm{C}$ for $10 \mathrm{~min}$. After amplification, the two products of each sample were mixed together and subjected to electrophoresis using a $1.5 \%$ agarose gel. The correct band was excised, purified using a gel extraction kit (Axygen, USA), and quantified with the Nanodrop 2000 spectrophotometer. All amplicons were pooled together with an equal molar amount for each sample and sequencing using an Illumina Miseq system at Guangdong Meilikang Bio-Science, Ltd., China.

\section{Data analysis}

The raw sequencing reads were merged using FLASH-1.2.8 software (Magoc and Salzberg, 2011) and per-processed for removing low-quality sequences using QIIME 
pipeline version 1.9.0 (Caporaso et al., 2010) as previously described (Ni et al., 2017; Huang et al., 2018; Xiang et al., 2018). Chimera sequences were identified and removed before further analysis using the Uchime algorithm (Edgar et al., 2011). The highquality sequences were clustered into operational taxonomic units (OTUs) at 97\% identity using UPARSE software (Edgar, 2013). Then all samples were randomly resampled to obtain the same number of sequences to overcome the influence of sequencing depth on results. Each OTU was assigned taxonomic information using the RDP classifier (Wang et al., 2007) with Greengenes database gg_13_8.

Principal component analysis (PCA) and non-parametric multivariate analysis of variance (MANOVA) (Anderson, 2001) were used to analyze the difference of microbiota among different groups and were conducted using $\mathrm{R}$ 3.5.1 with vegan package (Dixon, 2003). The box plots were drawn to show the relative abundances of significantly different OTUs among groups using STAMP software (Parks et al., 2014). And the statistically significant markers were added to the box plots using and Adobe Illustrator CS5 software according to the post-hoc test results.

All DNA datasets have been submitted to the NCBI Sequence Read Archive database under accession number SRP160514.

\section{Results and discussion}

\section{Composition of norfloxacin resistant bacteria in pond sediments}

Removing low-quality and chimera sequences, 346,643 high-quality sequences were obtained from the 18 samples. Finally, each sample was randomly resampled 11,000 sequences to further analysis. Except for little sequences $(0.97 \pm 0.38 \%$, mean \pm S.E. $)$ could not classified into an explicit phylum, other sequences were classified into 2 Archaea and 65 Bacteria phyla. However, according to previous definition by other researchers (Huang et al., 2018; Xiang et al., 2018), only 15 phyla - Crenarchaeota, Euryarchaeota, Acidobacteria, Actinobacteria, Bacteroidetes, Chlorobi, Chloroflexi, Cyanobacteria, Firmicutes, Nitrospirae, OP8, Planctomycetes, Proteobacteria, Spirochaetes, and Verrucomicrobia - dominated the sediment microbiotas (their relative abundances were more than $1 \%$ in at least one sample; Fig. 2). They contained up to $98.19 \pm 0.72 \%$ of the sequences.

Total of 35,194 OTUs were detected from the 18 sediment microbiotas. However, only 48 OTUs dominated the microbiotas (their relative abundances were more than $1 \%$ in at least one sample; Fig. 3). They contained up to $67.16 \pm 5.79 \%$ of the sequences. Lots of the dominant OTUs were reported as fish and mammal potentially pathogenic bacterial species, such as Acinetobacter sp., Lactococcus sp., Escherichia sp., Burkholderia sp., Streptomyces lanatus, Bacteroides sp., and Ruminococcus sp. (Slots and Listgarten, 1988; Kofteridis et al., 2007; Anandham et al., 2010; Fishbain and Peleg, 2010; Sudheesh et al., 2012; Woods and Sokol, 2006; Titécat et al., 2014; Li et al., 2017). And some of them were reported with multi-drug resistance (Li et al., 2017). In addition, potential plant bacterial pathogen Erwinia sp. and Ralstonia sp. (Swanson et al., 2005; Amin et al., 2011; Kube et al., 2010) also dominated the microbiota. Their norfloxacin resistance increased the bacterial infected risk of fish and plants.

Although norfloxacin is a broad-spectrum antibiotic, especially has a strong bactericidal effect to Gram-negative bacteria, most dominant OTUs were Gramnegative bacteria. This result implied that norfloxacin resistance was widespread in Gram-negative bacteria in the fish pond sediments located at southern China. 


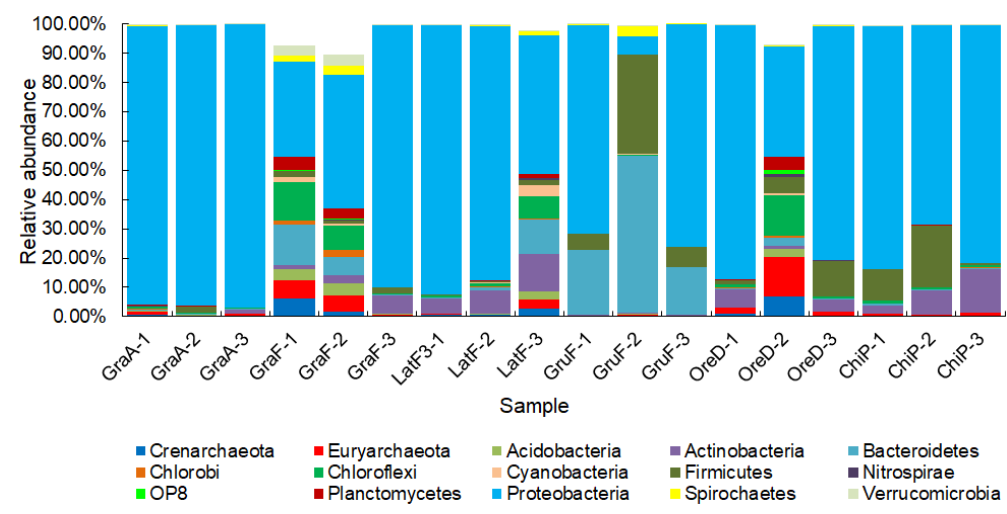

Figure 2. Dominant phyla of norfloxacin resistant bacteria in Chinese subtropical pond sediments. The sediment samples were collected from 5 fish ponds (GraA, GraF, LatF, GruF,

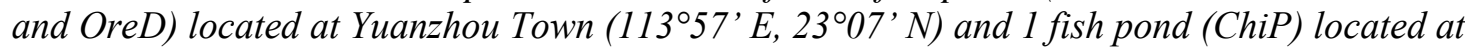
Huicheng District $\left(114^{\circ} 23^{\prime}\right.$ E, $\left.23^{\circ} 05^{\prime} N\right)$, in Huizhou, a subtropical city in southern China on January 22, 2016. The pond GraA mainly farmed grass carp (Ctenopharyngodon idellus) and tilapia (Tilapia mossambica). The pond GraF farmed fries of grass carp. The pond LatF farmed weever (Lateolabrax japonicus). The pond GruF farmed fries of crucian carp (Carassius auratus). The pond OreD farmed tilapia (Tilapia mossambica). The pond ChiP farmed a mixture of multiple fishes

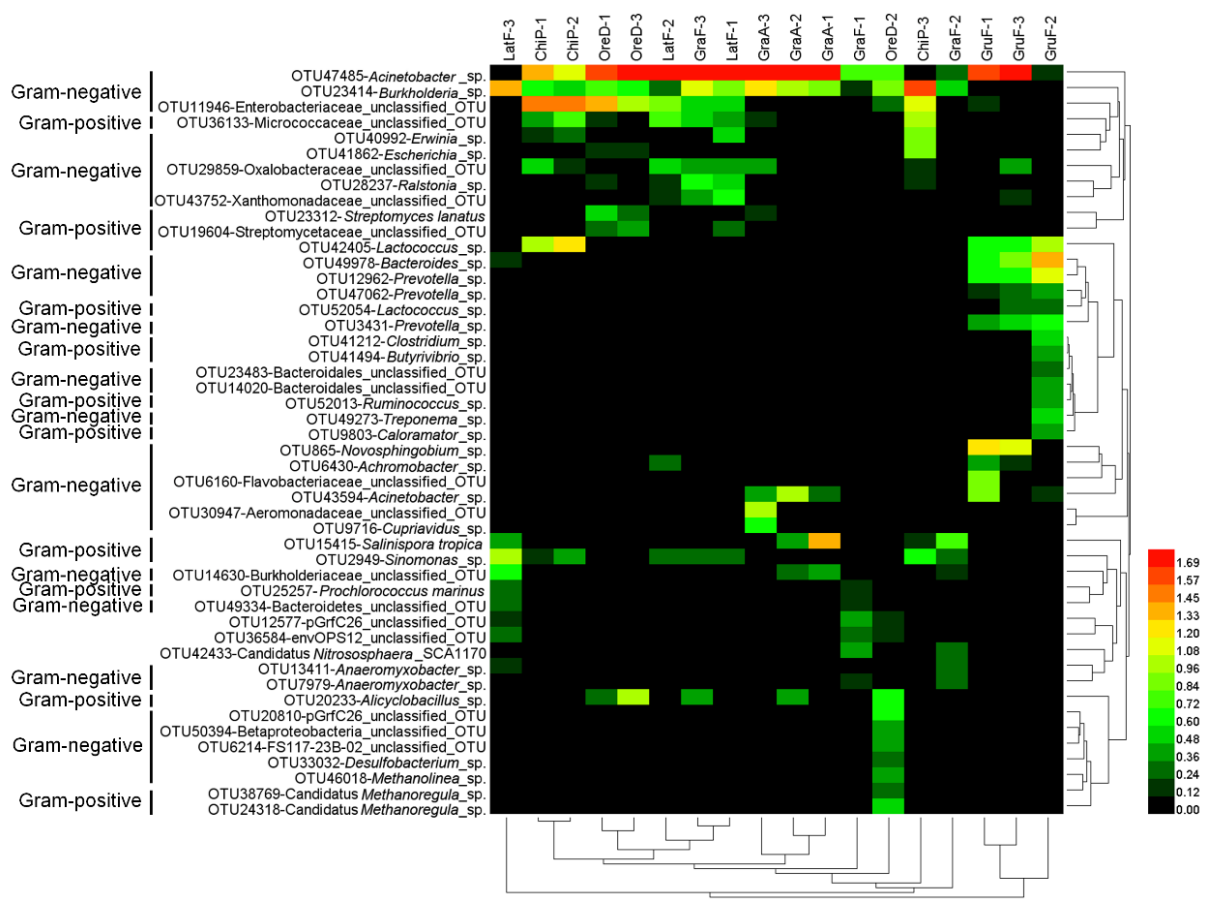

Figure 3. Heat map profile showed dominant OTUs of norfloxacin resistant bacteria in pond sediments. The data was transformed according to the equation $\log _{10}$ (relative abundance $\times 100$ $+1)$ to reduce the magnitude of extremum. The sediment samples were collected from 5 fish

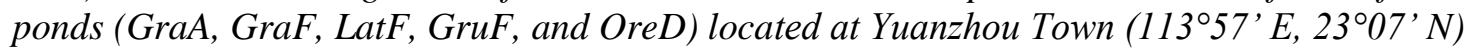
and 1 fish pond (ChiP) located at Huicheng District (114 $23^{\circ}$ 'E, $\left.23^{\circ} 05^{\prime} \mathrm{N}\right)$, in Huizhou, a subtropical city in southern China on January 22, 2016. The pond GraF farmed fries of grass carp. The pond LatF farmed weever (Lateolabrax japonicus). The pond GruF farmed fries of crucian carp (Carassius auratus). The pond OreD farmed tilapia (Tilapia mossambica). The pond ChiP farmed a mixture of multiple fishes 


\section{Different of norfloxacin resistant bacteria among different ponds}

Mechanisms forming and maintaining bacterial bio-diversity are the basic issue of microbial ecology (Ni et al., 2014, 2016; Wu et al., 2017).

(A)

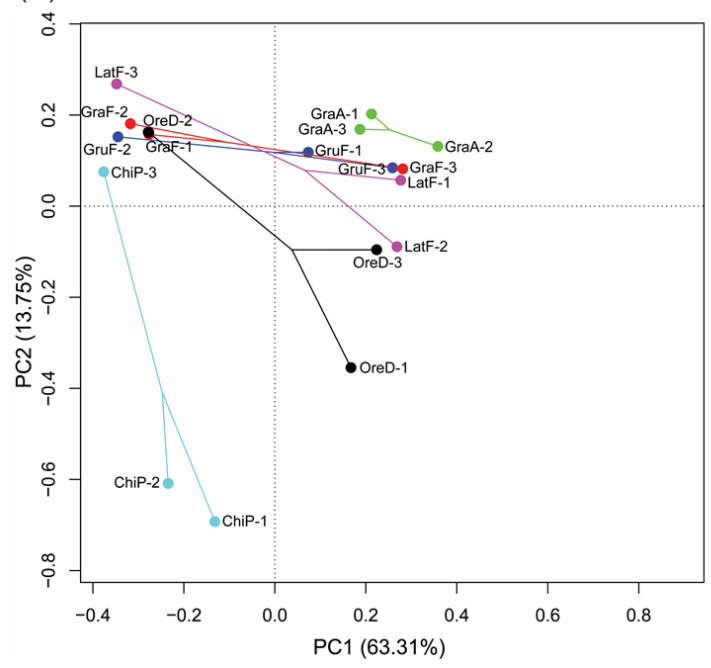

(B)

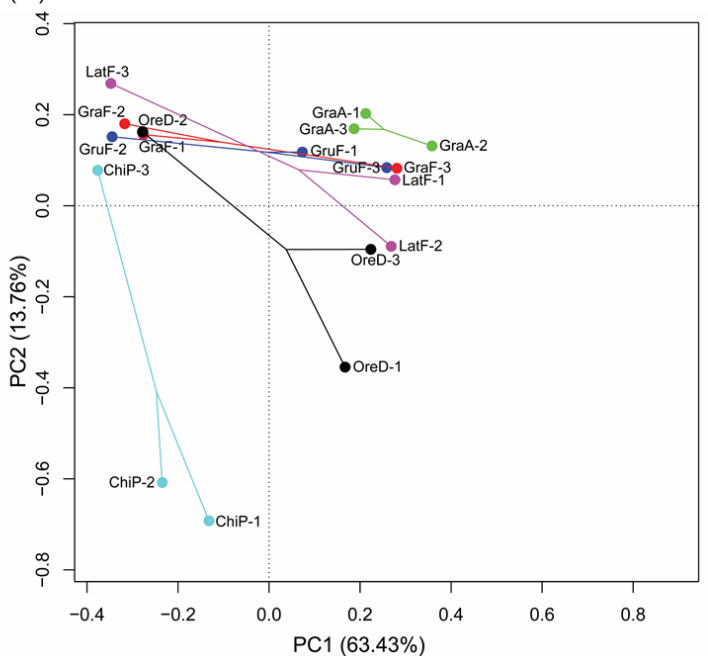

(C)

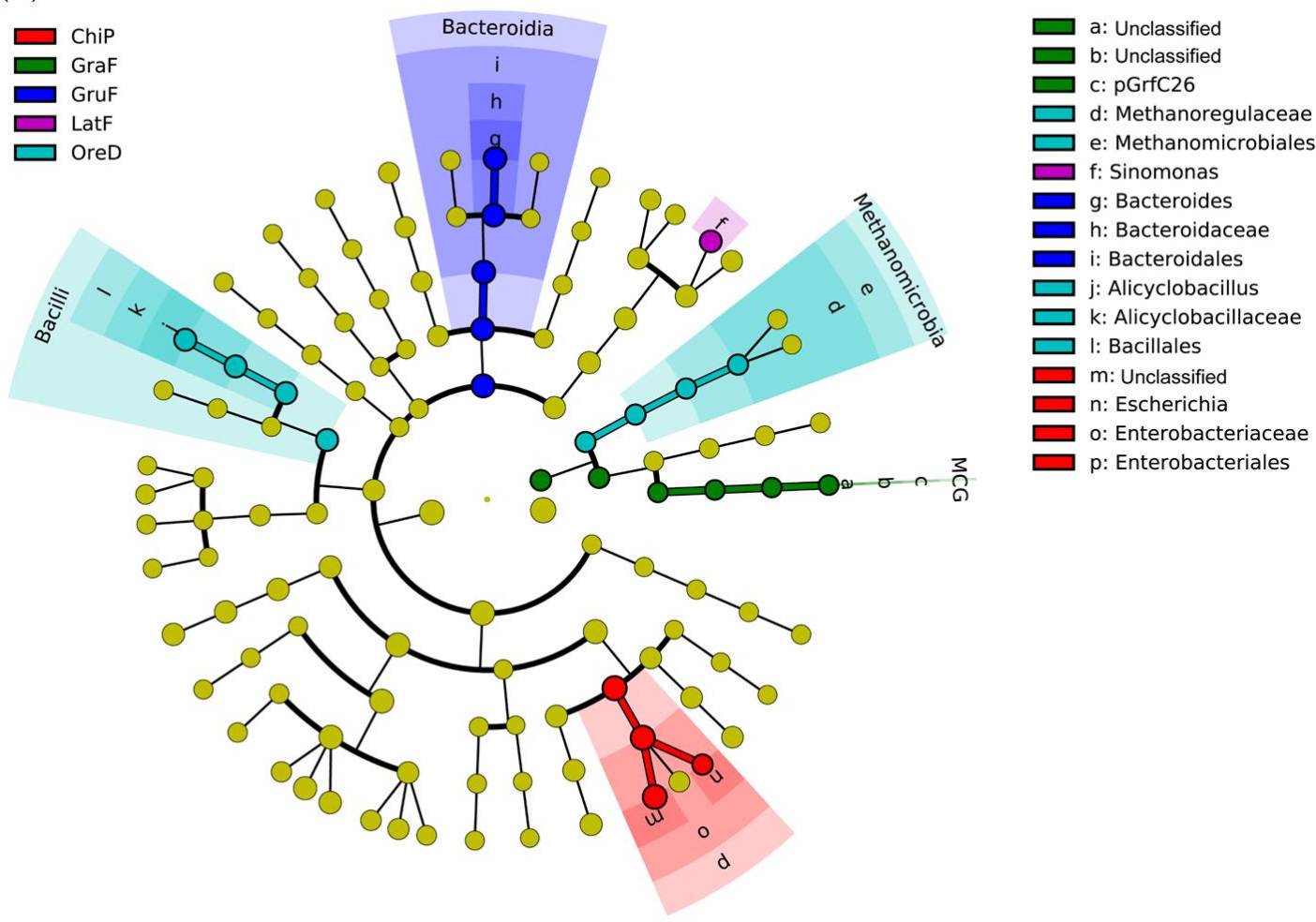

Figure 4. PCA profile based on OTUs (A) and based on dominant OTUs (B), and LEfSe profile based on dominant OTUs $(C)$ showed differences of norfloxacin resistant bacteria in pond sediments. The sediment samples were collected from 5 fish ponds (GraA, GraF, LatF, GruF, and OreD) located at

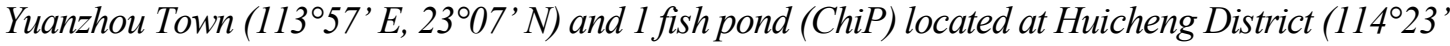
E, $23^{\circ} 05^{\prime}$ N), in Huizhou, a subtropical city in southern China on January 22, 2016. The pond GraF farmed fries of grass carp. The pond LatF farmed weever (Lateolabrax japonicus). The pond GruF farmed fries of crucian carp (Carassius auratus). The pond OreD farmed tilapia (Tilapia mossambica). The pond ChiP farmed a mixture of multiple fishes 
Geographical isolation is one of the primary factors that restrict microbial distribution and emerge a significant distance-decay relationship regarding microbial community similarity (Bell, 2010). However, protesters claim microorganisms are cosmopolitan, and spatial patterns of microbial diversity are driven by environmental heterogeneity (Green and Bohannan, 2006). Our results showed that although significant differences of sediment microbiotas were detected among different ponds both based on the OTU compositions (MANOVA, $F=1.851, p=0.002$; Fig. 4A) and based on the dominant OTU compositions (MANOVA, $F=1.926, p=0.016 ;$ Fig. $4 B$ ). And Bacteroides sp. was significantly enhanced at pond GruF, Alicyclobacillus sp. and an unidentified OTUs in family Methanoregulaceae was significantly enhanced at pond OreD, and Escherichia sp. and an unidentified OTUs in family Enterobacteriaceae was significantly enhanced at pond Chip (Fig. 4C). However, the microbiotas from the same pond did not cluster together except for those from pond GraA (Fig. 4A and B). These results showed that environmental heterogeneity was the major factor that casted the spatial patterns of microbial diversity.

\section{Conclusion}

In conclusion, we firstly investigated the norfloxacin resistant bacteria in fish pond sediments using the method that connected selective culture and high-throughput sequencing. Our results showed norfloxacin resistance was widespread in Gramnegative bacteria, such as Acinetobacter sp. and Burkholderia sp., in fish pond sediments located at southern China. This increased bacterial infected risk of farmed fish. In addition, mechanisms of these bacteria to resistant to norfloxacin and how to reduce the norfloxacin resistant bacteria are still needed to further study.

Acknowledgements. This work was supported by the Huizhou Science and Technology Planning Project (grant number 2017C0423039, 2016X0419034), and the Major Cultivation Projects of Huizhou University (grant number hzux1201520). The authors thank Dr. Jiajia Ni at Guangdong Meikang BioScience, Inc. for assistance with data analysis and figure preparation.

\section{REFERENCES}

[1] Amin, N. M., Bunawan, H., Redzuan, R. A. et al. (2011): Erwinia mallotivora sp., a new pathogen of papaya (Carica papaya) in Peninsular Malaysia. - International Journal of Molecular Sciences 12(1): 39-45.

[2] Anandham, R., Weon, H., Kim, S. et al. (2010): Acinetobacter brisouii sp. nov., isolated from a wetland in Korea. - Journal of Microbiology 48(1): 36-39.

[3] Bell, T. (2010): Experimental tests of the bacterial distance-decay relationship. - ISME Journal 4(11): 1357-1365.

[4] Caporaso, J. G., Kuczynski, J., Stombaugh, J. et al. (2010): QIIME allows analysis of high-throughput community sequencing data. - Nature Methods 7: 335-336.

[5] Cheng, W., Li, J., Wu, Y. et al. (2016): Behavior of antibiotics and antibiotic resistance genes in eco-agricultural system: A case study. - Journal of Hazardous Materials 304: 1825.

[6] Dixon, P. (2003): VEGAN, a package of R functions for community ecology. - Journal of Vegetation Science 14(6): 927-930.

[7] Edgar, R. C. (2013): UPARSE: Highly accurate OTU sequences from microbial amplicon reads. - Nature Methods 10: 996-998. 
[8] Edgar, R. C., Haas, B. J., Clemente, J. C. et al. (2011): UCHIME improves sensitivity and speed of chimera detection. - Bioinformatics 27: 2194-2200.

[9] Fang, Y., Xu, M., Chen, X. et al. (2015): Modified pretreatment method for total microbial DNA extraction from contaminated river sediment. - Frontiers of Environmental Science \& Engineering 9: 444-452.

[10] FAO (2014): The State of World Fisheries and Aquaculture 2014. - Food and Agricultural Organization of the United Nations, New York.

[11] Far, S. A. H. E., Khalil, R. H., Saad, T. T. et al. (2015): Occurrence, characterization and antibiotic resistance patterns of bacterial communities encountered in mass kills of pond cultured Indian prawn (Fenneropenaeus indicus) at Damietta governorate, Egypt. International Journal of Fisheries and Aquatic Studies 2(4): 271-276.

[12] Fishbain, J., Peleg, A. Y. (2010): Treatment of Acinetobacter infections. - Clinical Infectious Diseases 51(1): 79-84.

[13] Green, J., Bohannan, B. J. M. (2006): Spatial scaling of microbial biodiversity. - Trends in Ecology \& Evolution 21(9): 501-507.

[14] Goossens, H., Ferech, M., Vander Stichele, R. et al. (2005): Outpatient antibiotic use in Europe and association with resistance: a cross-national database study. - Lancet 365(9459): 579-587.

[15] Guo, H., Zhang, Q. (2009): Residues regulation of norfloxacin in Ctenopharyngodon idellus. - Journal of Aquaculture 30(10): 24-26.

[16] Harvell, C. D., Kim, K., Burkholder, J. M. et al. (1999): Emerging marine diseases climate links and anthropogenic factors. - Science 285(5433): 1505-1510.

[17] Huang, R., Li, T., Ni, J. et al. (2018): Different sex-based responses of gut microbiota during the development of hepatocellular carcinoma in liver-specific Tscl-knockout mice. - Frointiers in Microbiology 9: 1008.

[18] Kofteridis, D. P., Maraki, S., Scoulica, E. et al. (2007): Streptomyces pneumonia in an immunocopetent patient: a case report and literature review. - Diagnostic Microbiology and Infectious Disease 59(4): 459-462.

[19] Kube, M., Migdoll, A. M., Gehring, I. et al. (2010): Genome comparison of the epiphytic bacteria Erwinia billingiae and E. tasmaniensis with the pear pathogen E. pyrifoliae. BMC Genimics 11: 393.

[20] Kumarasamy, K. K., Toleman, M. A., Walsh, T. R. et al. (2010): Emergence of a new antibiotic resistance mechanism in India, Pakistan, and the UK: a molecular, biological, and epidemiological study. - Lancet Infectious Diseases 10(9): 597-602.

[21] Laxminarayan, R., Duse, A., Wattal, C. et al. (2013): Antibiotic resistance - the need for global solution. - Lancet Infectious Diseases 13(12): 1057-1098.

[22] Levy, S. B., Marshall, B. (2004): Antibacterial resistance worldwide: causes, challenges and responses. - Nature Medicine 10(12): 122-129.

[23] Li, J., Cao, J., Wang, X. et al. (2017): Acinetobacter pittii, an emerging new multi-drug resistant fish pathogen isolated from diseased blunt snout bream (Megalobrama amblycephala Yih) in China. - Applied Microbiology and Biotechnology 101(16): 64596471.

[24] Lin, J., Pan, H., Liu, S. et al. (2010): Effects of light and microbial activity on the degradation of two fluoroquinolone antibiotics in pond water and sediment. - Journal of Environmental Science and Health Part B 45: 456-465.

[25] Lu, S., Liao, M., Xie, C. et al. (2015): Seasonal dynamics of ammonia-oxidizing microorganisms in freshwater aquaculture ponds. - Annals of Microbiology 65(2): 651657.

[26] Ma, G., Qu, Q., Wu, W. et al. (2001): Application of antibiotics in aquaculture. - Chinese Journal of Fisheries 14: 73-76.

[27] Ma, Y., Feng, B., Li, J. et al. (2012): Effects of norfloxacin on the quantity and drugresistance of bacteria isolated from soil. - Journal of Traditional Chinese Veterinary Medicine 31(1): 9-12. 
[28] Magoc, T., Salzberg, S. L. (2011): FLASH: Fast length adjustment of short reads to improve genome assemblies. - Bioinformatics 27: 2957-2963.

[29] Mathew, A. G., Cissell, R., Liamthong, S. (2007): Antibiotic resistance in bacteira associated with food animals: a United States perspective of livestock production. Foodborne Pathogens and Disease 4(2): 115-133.

[30] Meyer, F. P. (1991): Aquaculture disease and health management. - Journal of Animal Science 69(10): 4201-4208.

[31] Moore, J. E., Huang, J., Yu, P. et al. (2014): High diversity of bacterial pathogens and antibiotic resistance in salmonid fish farm pond water as determined by molecular identification employing $16 \mathrm{~S}$ rDNA PCR, gene sequencing and total antibiotic susceptibility techniques. - Ecotoxicology and Environmental Safety 108: 281-286.

[32] Neela, F. A., Banu, M. N. A., Rahman, M. A. et al. (2015): Occurrence of antibiotic resistant bacteria in pond water associated with integrated poultry-fish farming in Bangladesh. - Sains Malaysiana 44(3): 371-377.

[33] Ni, J., Yan, Q., Yu, Y. et al. (2014): Fish gut microecosystem: a model for detecting spatial pattern of microorganisms. - Chinese Journal of Oceanology and Limnology 32(1): 54-57.

[34] Ni, J., Xu, M., He, Z. et al. (2016): Novel insight into evolutionary process from average genome size in marine bacterioplanktonic biota. - Applied Ecology and Environmental Research 14(2): 65-75.

[35] Ni, J., Li, X., He, Z. et al. (2017): A novel method to determine the minimum number of sequences required for reliable microbial community analysis. - Journal of Microbiological Methods 139: 196-201.

[36] Ni, J. J., Li, X. J., Chen, F. et al. (2018): Community structure and potential nitrogen metabolisms of subtropical aquaculture pond microbiota. - Applied Ecology and Environmental Research (in press).

[37] Ortiz, J., Vila, M. C., Soriano, G. et al. (1999): Infections caused by Escherichia coli resistant to norfloxacin in hospitalized cirrhotic patients. - Hepatology 29(4): 1064-1069.

[38] Parks, D. H., Tyson, G. W., Hugenholtz, P. et al. (2014): STAMP: statistical analysis of taxonomic and functional profiles. - Bioinformatics 30(21): 3123-3124.

[39] Patil, H. J., Benet-Perelberg, A., Naor, A. et al. (2016): Evidence of increased antibiotic resistance in phylogenetically-diverse Aeromonas isolates from semi-intensive fish ponds treated with antibiotics. - Frontiers in Microbiology 7: 1875.

[40] Slots, J., Listgarten, M. A. (1988): Bacteroides gingivalis, Bacteroides intermedius and Actinobacillus actinomycetemcomitans in human periodontal diseases. - Journal of Clinical Periodontology 15(2): 85-93.

[41] Song, C., Zhang, C., Fan, L. et al. (2016): Occurrence of antibiotics and their impacts to primary productivity in fishponds around Tai Lake, China. - Chemosphere 161: 127-135.

[42] Spongberg, A. L., Witter, J. D., Acuña, J. et al. (2011): Reconnaissance of selected PPCP compounds in Costa Rican surface waters. - Water Research 45: 6709-6717.

[43] Subasinghe, R. (1997): Fish Health and Quarantine; Review of the State of the World Aquaculture. - FAO Fisheries Circular. Food and Agriculture Organization of the United Nations 886: 45-49.

[44] Sudheesh, P. S., Al-Ghabshi, A., Al-Mazrooei, N. et al. (2012): Comparative pathogenomics of bacteria causing infectious diseases in fish. - International Journal of Evolutionary Biology 2012: 457264.

[45] Swanson, J. K., Yao, J., Tans-Kersten, J. et al. (2005): Behavior of Ralstonia solanacearum race 3 biovar 2 during latent and active infection of geranium. Phytopathology 95(2): 136-143.

[46] Titécat, M., Wallet, F., Vieilard, M. H. et al. (2014): Ruminococcus gnavus: an unusual pathogen in septic arthritis. - Anaerobe 30: 159-160. 
[47] Wahid, M. A., Basri, Z. D. M., Halip, A. A. et al. (2014): Antibiotic Resistance Bacteria in Coastal Shrimp Pond Water and Effluent. - In: Hassan, R., Yusoff, M., Alisibramulisi, A. et al. (ed.) InCIEC 2014. Springer, Singapore.

[48] Wang, Q., Garrity, G. M., Tiedje, J. M. et al. (2007): Naïve Bayesian classifier for rapid assignment of rRNA sequences into the new bacterial taxonomy. - Applied and Environmental Microbiology 73: 5261-5267.

[49] Wei, R., Ge, F., Huang, S. et al. (2011): Occurrence of veterinary antibiotics in animal wastewater and surface water around farms in Jiangsu province, China. - Chemosphere 82: $1408-1414$.

[50] Woods, D. E., Sokol, P. A. (2006): The Genus Burkholderia. - In: Dworkin, M., Falkow, S., Rosenberg, E. et al. (ed.) The Prokaryotes. Springer, New York.

[51] Wu, L., Sun, Q., Ni, J. (2017): Not all of the rare operational taxonomic units (OTUs) play the same role in maintaining community stability. - Applied Ecology and Environmental Research 15(1): 105-112.

[52] Xiang, J., He, T., Wang, P. et al. (2018): Opportunistic pathogens are abundant in the gut of cultured giant spiny frog (Paa spinosa). - Aquaculture Research 49: 2033-2041.

[53] Yang, Y., Cao, X., Lin, H. et al. (2016): Antibiotics and antibiotic resistance genes in sediment of Honghu Lake and east Dongting Lake, China. - Microbial Ecology 72(4): 791-801.

[54] Zhang, Y. B., Li, Y., Sun, X. L. (2011): Antibiotic resistance of bacteria isolated from shrimp hatcheries and cultural ponds on Donghai Island, China. - Marine Pollution Bulletin 62(11): 2299-2307.

[55] Zhang, Y., Rong, C., Song, Y. et al. (2017): Oxidation of the antibacterial agent norfloxacin during sodium hypochlorite disinfection of marine culture water. Chemosphere 182: 245-254. 